\title{
Erectile dysfunction, diabetes and cardiovascular risk
}

\author{
GEOFFREY IAN HACKETT
}

\begin{abstract}
Erectile dysfunction (ED) occurs in up to $75 \%$ of men with type 2 diabetes (T2DM) and has a complex pathogenesis owing to a combination of microvascular, macrovascular, endocrine and neuropathic disease. ED is established as an independent marker for the development of coronary artery disease (CAD) occurring on average 3-5 years before the onset of CAD. Thus, timely detection of ED offers an opportunity for early intervention, thereby reducing morbidity associated with CAD. The average UK male, however, suffers for 3 years before discussing symptoms of ED with a healthcare professional. The National Institute for Health and Care Excellence (NICE) recommends an annual review of ED symptoms in susceptible patients with T2DM with an appropriate discussion of management options. Screening questions regarding ED were introduced in the $\mathbf{2 0 1 3}$ Quality Outcome Framework but were removed by NHS England in 2014 on grounds of 'simplification'. Response to treatment strategies for ED is poor in diabetes, and poor glycaemic control, long duration of disease and severity of complications is predictive of a poor treatment response. The concomitant presence of hypogonadism in over $40 \%$ of men with T2DM also makes ED difficult to treat in this group. Further, ED and severe hypogonadism have been shown to independently predict mortality in T2DM. Treatment for ED is more likely to be effective if given early, although complex regimens may be required.
\end{abstract}

Br J Diabetes 2016;16:52-57

Key words: erectile dysfunction, coronary artery disease, type 2 diabetes

\section{Background}

Erectile dysfunction (ED) is the inability to obtain and maintain a penile erection that allows adequate sexual intercourse. ${ }^{1}$ Data from a large community-based observational study found that $52 \%$ of non-institutionalised men between the age of 40 and 70 years reported ED. ${ }^{2}$ Diabetes mellitus is strongly associated with

Heartlands Hospital, Birmingham and University of Bedfordshire, UK

Address for correspondence: Professor Geoffrey Hackett Good Hope Hospital, Rectory Rd, Sutton Coldfield B75 7RR, UK Tel: +44 (0)1543 432757 Fax: +44 (0)1543 433303

E-mail: geoffhackett@doctors.org.uk

http://dx.doi.org/10.15277/bjd.2016.076
Figure 1. Association of depression and diabetes complications: a meta-analysis

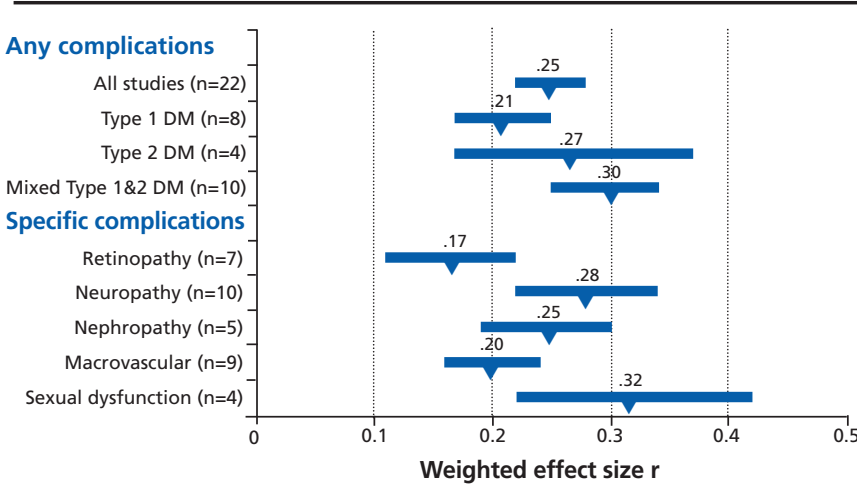

Reproduced with permission from De Groot et al. ${ }^{7}$

the development of ED, with a reported prevalence of ED of $35-90 \%$ in those with diabetes in different populations.3,4 The pathophysiology of ED in diabetes is multifactorial. Under normal circumstances, both biological and psychological factors work synchronously resulting in an erection. ${ }^{5}$ Psychological arousal results in a biological cascade that involves parasympathetic activation and consequent nitric oxide (NO) release from local endothelial cells. NO mediates smooth muscle and vascular relaxation resulting in increased arterial flow to the penile corpora cavernosa. The increasing blood flow impedes venous return via compression of penile venules, thus maintaining an erection..$^{5} \mathrm{ED}$ can therefore develop in diabetes owing to an interplay between neuropathy, vasculopathy, hypogonadism, endothelial dysfunction and psychological factors.

Depression is more common in people with diabetes than in those without, and a meta-analysis found twice the odds of depression in diabetes compared with controls (odds ratio (OR) 2.0, $95 \% \mathrm{Cl} 1.8$ to 2.2). ${ }^{6}$ Studies have shown that sexual function is more closely linked with depression than other diabetes complications both in men and women (Figure 1), yet antidepressant medications frequently adversely affect sexual function. ${ }^{7}$ Recent work also increasingly recognises ED as an independent risk factor for coronary artery disease (CAD), which appears to be particularly significant in younger men and those with diabetes who are already at high risk of developing CAD. 8,9

Here we will review the evidence linking $E D$ to $C A D$ and explore the relationship between diabetes control and development of ED and other sexual dysfunctions. Further, we will high- 
Figure 2. Interplay of cardiovascular risk factors, endothelial dysfunction and erectile dysfunction

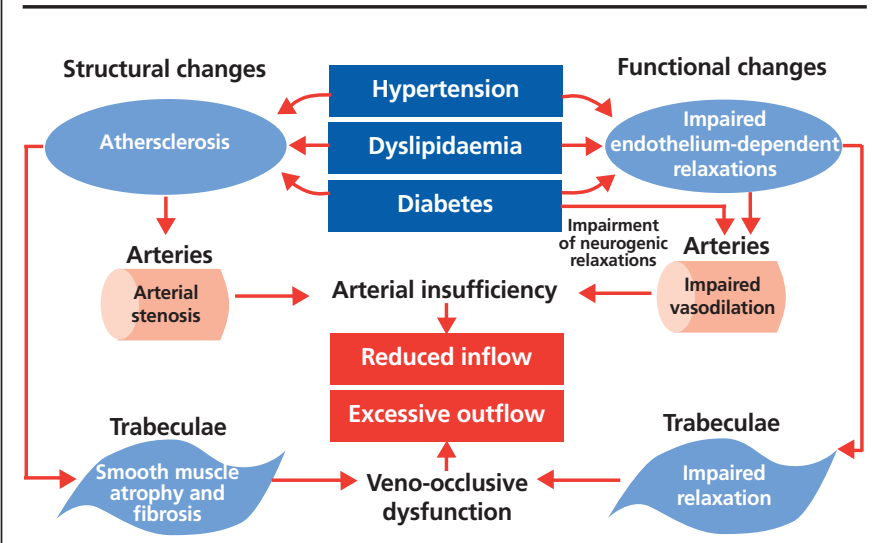

Adapted from Saenz de Tejada et al. ${ }^{10}$

light the role of hypogonadism in the context of type 2 diabetes mellitus (T2DM) and its link with ED prior to discussing treatment strategies for ED with a focus on diabetes and cardiovascular disease (CVD) risk reduction.

\section{ED as a risk factor for CAD}

The development of ED is attributable to neural, vascular, hormonal, metabolic and psychogenic factors, all mediated through endothelial and smooth muscle dysfunction (Figure 2). ${ }^{10}$ Early intervention at the stage of endothelial dysfunction may potentially reverse ED but, at the stage of fixed atherosclerosis, reversibility is unlikely. ${ }^{11,13}$ The arterial size hypothesis explains why a $50 \%$ penile artery occlusion will manifest symptoms of ED 3-5 years before symptoms of CAD develop in the larger coronary arteries (Figure 3). ${ }^{11,12,14}$ ED has been shown to be associated with the severity of ischaemic heart disease in terms of plaque burden and the number of coronary arteries affected. ${ }^{12}$ Screening for ED offers an important window of opportunity for intervention to prevent coronary events, especially in younger men where the predictive value of ED is greatest. ${ }^{13}$

A large body of evidence suggests that the presence of ED increases the risk of CAD by $50 \% .{ }^{15}$ Ma et al. ${ }^{16}$ found that the predictive value of ED is greater in men with T2DM and no known CAD (Figure 4). Indeed, the authors found that ED was an independent risk factor for new onset CAD events, equivalent to an established risk factor of incident hypertension and greater than microalbuminuria. Conventional (CVD) risk markers and scores, however, do not account for ED. Araujo et al. ${ }^{17}$ aimed to test the hypothesis that ED improves CVD prediction beyond traditional risk factors. In a prospective study population, the authors found that ED was significantly associated with the incidence of CVD; however, ED detection does not confer any additional benefit in predicting future CVD compared with traditional risk factors. The Princeton III guidelines ${ }^{18}$ reaffirmed ED as a risk factor for CVD, with the presence of ED increasing the relative risk of CAD by $1.46(95 \% \mathrm{Cl} 1.31$ to $1.63 ; p<0.01)$.
Figure 3. Erectile dysfunction (ED) occurs 3-5 years before coronary artery disease (CAD)

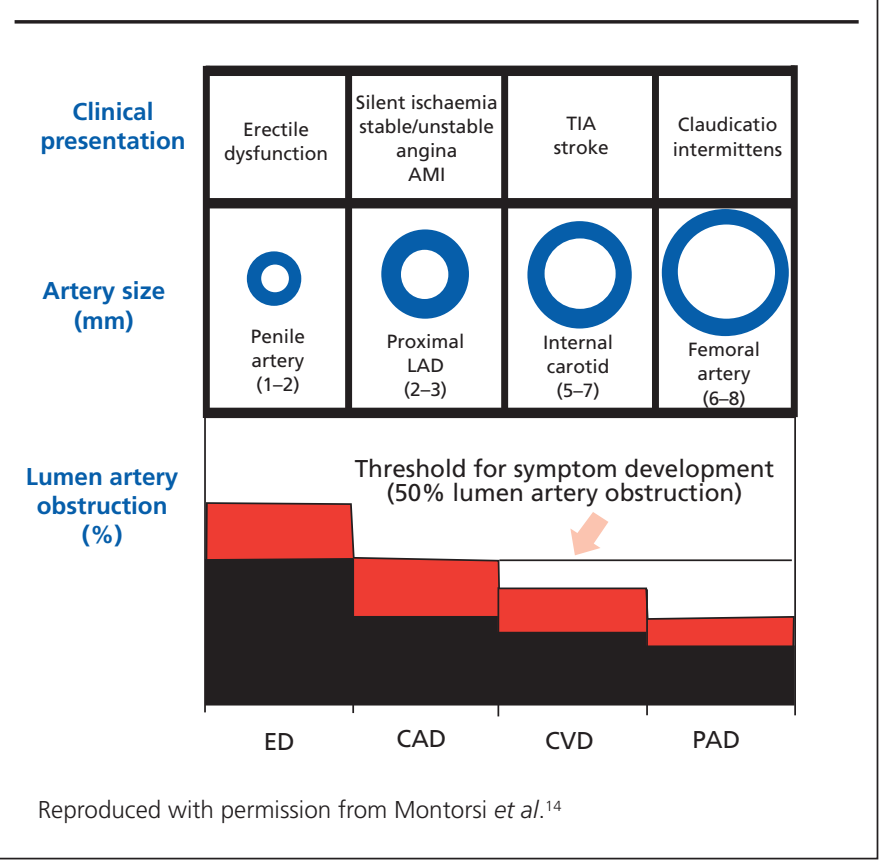

Figure 4. Cumulative hazard ratio of coronary heart disease (CHD) events stratified by erectile dysfunction

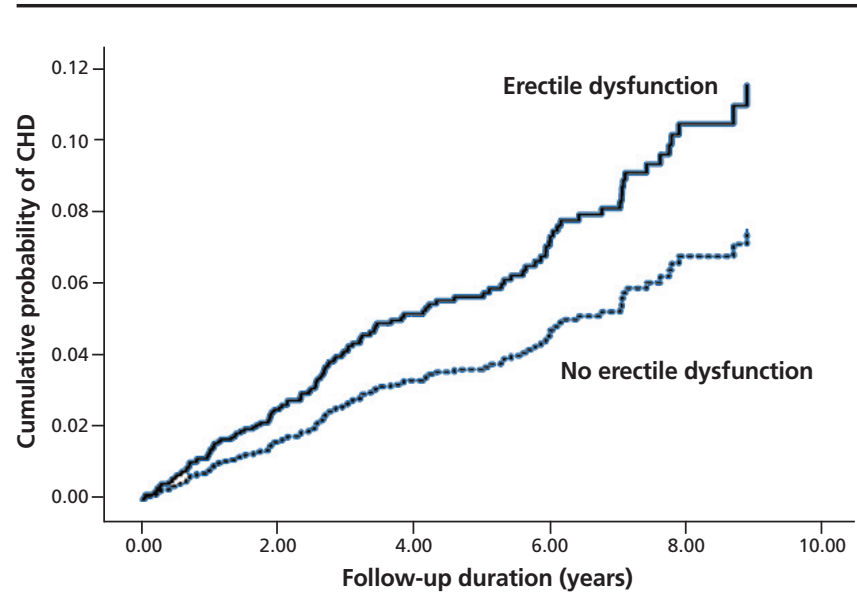

Reproduced with permission from Ma et al. ${ }^{16}$

Given a common pathophysiological link of endothelial dysfunction between ED and CAD in addition to a strong epidemiological association, Jackson et al. ${ }^{19}$ recommended that ED should be considered a 'cardiac equivalent' and aggressive risk reduction therapy should be initiated for those with ED, specifically younger men. With regard to detecting the presence of silent $C A D$ in men with $E D$, stress testing on exercise will only identify those lesions influencing flow (>50-70\% stenosis). Jackson et al. ${ }^{19}$ provide an algorithm for the cardiovascular assessment of the patient with ED, targeting aggressive intervention in the younger patient (Figure 5). 
Figure 5. Algorithm for cardiovascular assessment of men with erectile dysfunction

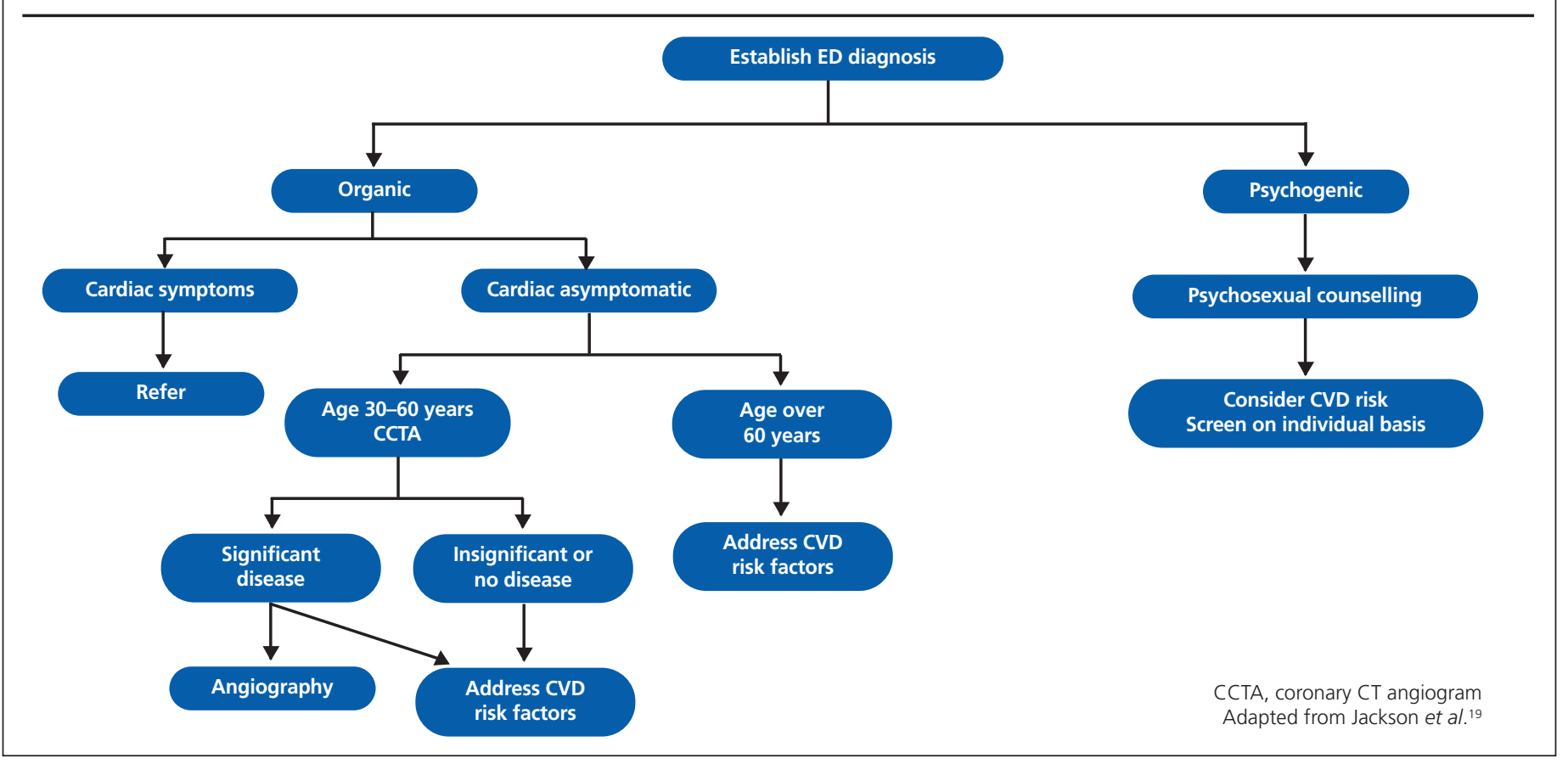

\section{ED associated with diabetes control, complications and medications}

Studies suggest a link between glycaemic control and ED. ${ }^{19,20}$ Lu et al. conducted a study involving 792 men, of whom $83.6 \%$ had some degree of ED, including $43 \%$ with serious ED. ${ }^{20}$ The study showed that, even after controlling for age and duration of diabetes, there was an association between glycated haemoglobin levels $\left(\mathrm{HbA}_{1 \mathrm{c}}\right)$ and $\mathrm{ED}(\mathrm{OR} 1.12,95 \% \mathrm{Cl} 1.01$ to 1.25$)$. The authors also performed subgroup analysis to investigate the association between age and severe ED. In patients aged $<60$ years, $\mathrm{HbA} 1 \mathrm{c}$, age and duration of diabetes were independent predictors of severe ED. However, for patients aged $>60$ years, only age and duration of diabetes were independent predictors of severe ED. ${ }^{20}$ In patients with diabetes, the severity of ED has been linked to the number of circulating endothelial microparticles. ${ }^{21}$

The medications that patients are receiving for treatment of diabetes and their complications may influence ED. In particular, ED has been associated with the use of $\beta$-blockers, thiazide diuretics, metformin, antidepressants, statins, fibrates and drugs used for neuropathic pain such as pregabalin, gabapentin and opiate analgesics. ${ }^{22}$ Other drugs may have a beneficial effect. In patients with hypertension and diabetes, a study showed that initiation of an angiotensin receptor blocker (valsartan) in patients on no other antihypertensives ( $n=952$ ) reduced the rate of ED from $65 \%$ to $45 \%$ $(p<0.0001) .^{23}$

\section{Hypogonadism in type 2 diabetes}

Hypogonadism is common in diabetes. Studies consistently show that, in patients with T2DM, 35\% have total testosterone (TT) levels below $12 \mathrm{nmol} / \mathrm{L}$ and $15 \%$ have TT levels below $8 \mathrm{nmol} / \mathrm{L} .{ }^{24,25} \mathrm{In}$ a study of 1,413 men, those in the first (lowest) tertile of low free testosterone (FT) and TT were four times more likely to have diabetes than those in the third tertile of low TT and FT. ${ }^{26}$ Furthermore, low FT and sex hormone binding globulin (SHBG) have been shown to predict the onset of diabetes in men in up to 10 years of followup (OR 1.58 for a decrease of $4 \mathrm{ng} / \mathrm{dL}$ FT and OR 1.89 for a decrease of $16 \mathrm{nmol} / \mathrm{L} \mathrm{SHBG).}{ }^{27}$ Treatment of severe hypogonadism with testosterone replacement may help to improve both sexual function and quality of life. In a double-blind placebo-controlled study, patients with severe hypogonadism $(T T<8 \mathrm{nmol} / \mathrm{L}$ or $\mathrm{FT}<180$ $\mathrm{pmol} / \mathrm{L}$ ) receiving testosterone undecanoate reported improved sexual function at 30 weeks follow-up, although there was no significant improvement in sexual function in patients with mild hypogonadism at baseline (TT 8.1-12 nmol/L or FT 181-250 $\mathrm{pmol} / \mathrm{L}){ }^{28}$ Another study showed that, in patients with $\mathrm{TT}<9.54$ $\mathrm{nmol} / \mathrm{L}$, treatment with testosterone gel was associated with improved responses to phosphodiesterase 5 (PDE5) inhibitors in comparison with placebo. ${ }^{29}$

In patients receiving testosterone replacement therapy (TRT), beneficial effects on reported quality of life and sexual interest may manifest as early as 3 weeks, although effects on erectile function may take up to 6 months. ${ }^{30}$ Improvement in quality of life with TRT has been reported to be higher at 52 weeks than at 30 weeks in diabetic patients, with the best results in patients without obesity and co-existent depression. This suggests that treatment may need to be given for a prolonged time. ${ }^{31}$

In view of the association between hypogonadism and diabetes, researchers have postulated whether TRT can also improve metabolic parameters in diabetes. Studies have shown an association between TRT and reductions in $\mathrm{HbA}_{1 \mathrm{c}}{ }^{32}$ improvement in insulin resistance ${ }^{33}$ and a reduction in body mass index. ${ }^{34} \mathrm{~A}$ large Australian study (T4DM) is currently underway to assess whether 
treatment of low testosterone in younger men can reduce the incidence of diabetes, and findings are due to be reported in 2017.

\section{Diabetes and other sexual dysfunctions}

In addition to ED, T2DM is associated with other sexual dysfunctions. Corona et al. conducted a prospective study of 499 patients with newly or recently diagnosed diabetes. ${ }^{35}$ They reported that, around the time of diagnosis of diabetes, the prevalence of premature ejaculation, delayed ejaculation and low sexual desire was $28.3 \%, 32.9 \%$ and $58.4 \%$, respectively. Sexual dysfunction preceded the diagnosis of diabetes in 30\%, and $45.3 \%$ had never consulted about sexual dysfunction. 35

T2DM has also been associated with diseases that can indirectly cause sexual dysfunction, such as balanitis and Peyronie's disease. In a study conducted in 1,137 Danish patients, a higher HbA 1c level was associated with an increased frequency of balanitis in patients with diabetes compared with those without (OR 1.25, Cl 1.09 to 1.44), despite adjustment for age, sex, body mass index, blood pressure, complications and antihypertensive treatment. ${ }^{36}$ The inflammation, pain and discharge related to fungal balanitis may adversely affect sexual function. Peyronie's disease, which may be associated with sexual dysfunction, is more common in diabetes, with a higher incidence related to a longer duration of diabetes and poor glycaemic control. ${ }^{37}$

\section{Treatment of ED in T2DM}

Treatment options for ED in T2DM include lifestyle changes and oral medications, amongst other treatments.

Wing et al. studied the effects of lifestyle interventions in obese patients with T2DM and ED. ${ }^{38} \mathrm{~A}$ cohort of patients in the intensive lifestyle intervention group (ILI) had group and individual sessions focusing on weight loss and exercise, whilst the control group of patients received diabetes support and education only (DSE). At 1 year, $8 \%$ of men in the ILI group reported worsening of erectile function, $70 \%$ reported no significant change and $22 \%$ reported some improvement. In the DSE group, $20 \%$ reported worsening of ED at 1 year, $57 \%$ reported no significant change and $23 \%$ reported improvement $(p=0.006)$. Thus, the effect of lifestyle intervention in ED is likely to be modest. ${ }^{38}$

For patients with hypogonadism, in the context of ED and diabetes, this should be treated as discussed previously. PDE5 inhibitors are generally considered first-line therapy for men with diabetes and ED in the absence of hypogonadism. ${ }^{39}$ They work by reducing breakdown of cyclic guanosine monophosphate (cGMP), a crucial second messenger in NO-mediated smooth muscle relaxation that is responsible for erection. All four of the currently available PDE5 inhibitors (sildenafil, tardenafil, tadalafil and avanafil) are safe and effective in diabetes. However, studies suggest that the response rate to PDE5 inhibitors is lower in patients with diabetes than in those without diabetes (63\% vs. 83\%).40,41 This may be because the response to PDE5 inhibitors relies on an intact neurogenic vascular response, whilst patients with diabetes commonly have endothelial and autonomic dysfunction. ${ }^{40,41}$ A combination of folic acid and tadalafil has been shown to be more effective than tadalafil alone in restoring erectile function in diabetic patients. ${ }^{42}$ Other strategies to improve the response to oral PDE5 inhibitors include addition of L-arginine or use of daily dosing of a combination of PDE5 inhibitors. ${ }^{43}$

In addition to improving ED, PDE5 inhibitors may reduce cardiovascular risk through a range of effects. They have been shown to reduce subclinical inflammation and thrombosis, ${ }^{44}$

Figure 6. Testosterone replacement therapy and mortality in UK men with type 2 diabetes mellitus
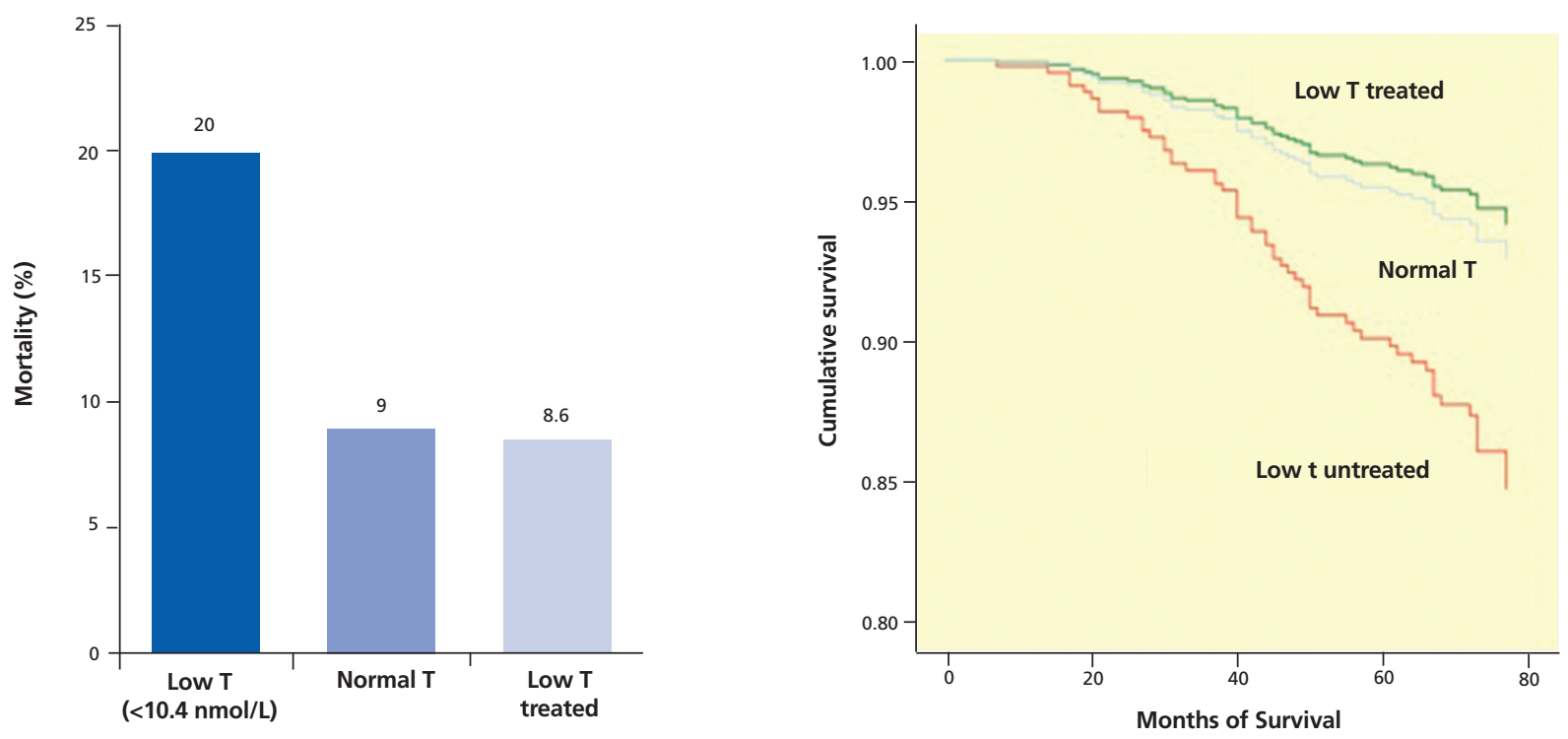

T, testosterone $\quad$ Reproduced with permission from Muraleedharan et al. ${ }^{48}$ 
Figure 7. Multivariate regression model for risk of mortality

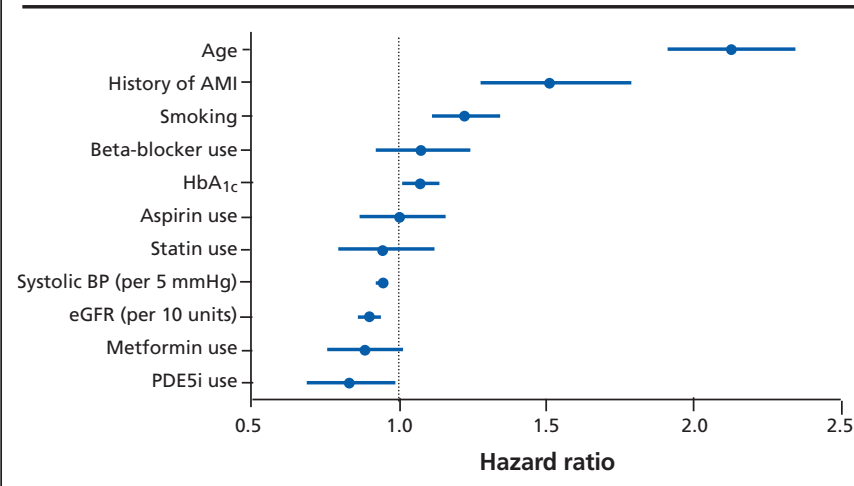

Reproduced with permission from Anderson et al. ${ }^{49}$

improve cardiac inotropism ${ }^{45}$ and have anti-remodelling effects. ${ }^{45}$ In patients with established CAD and T2DM, PDE5 inhibitors may help to reduce the incidence of major adverse cardiac events. ${ }^{12,46}$ In a study of 7,680 men with T2DM, 432 had a myocardial infarction over a follow-up period of 6.4 years. In this group, patients who were using PDE5 inhibitors had a 50\% lower mortality rate than those not on PDE5 inhibitors (hazard ratio 0.5 (95\% Cl 0.29 to $0.85, p=0.01) .{ }^{46}$ Two recent studies have shown reduced allcause mortality with TRT for low testosterone levels in US veterans ${ }^{47}$ and a UK population of men with T2DM (Figure 6). ${ }^{48}$ A recent study by Anderson et al. evaluated mortality data and events in terms of levels of $\Pi$ achieved after treatment and demonstrated that TRT impacts more on the chances of surviving major events rather than reducing absolute numbers (Figure 7). ${ }^{49}$

There is relatively little research on non-oral treatments such as vacuum therapy and self-injection therapy for ED in diabetes, so these are usually reserved as second-line treatment options. Reported satisfaction rates for vacuum devices vary between 35\% and $84 \% .{ }^{39}$ Long-term usage of vacuum devices is still higher than intracavernosal injections. ${ }^{39}$

\section{Conclusions}

ED is common and adversely affects patients psychologically and biologically. In particular, ED is an important predictor of prospective CVD in men. Anecdotal evidence suggests that current NICE guidance to assess ED annually and address contributory factors is not being comprehensively adhered to. Recent research, however, suggests that addressing low testosterone levels with TRT in the context of ED is associated with multiple small health benefits that may be equated to considerable benefit to patients. Furthermore, instituting therapy with TRT for low testosterone and treating ED with PDE5 inhibitors may be independently associated with a reduction in all-cause CVD mortality.

Conflict of interest Occasional speaker for Bayer, Lilly, and Menarini. Funding None.

\section{References}

1. NIH Consensus Conference. Impotence. NIH Consensus Development

\section{Key messages}

- $\quad$ The prevalence of ED in the primary care T2DM population is approximately $75 \%$

- The development of ED is related to duration and control of diabetes plus the severity of complications

- Development of ED is a strong predictor of future cardiovascular events particularly in younger men

- NICE guidance suggests annual assessment and discussion of therapeutic options for ED in all men with T2DM.

- Hypogonadism is found in over $40 \%$ of men with T2DM. Treatment with lifestyle change and Testosterone replacement improves ED and salvages patients who otherwise fail to respond to PDE5Is

- Recent evidence suggests that testosterone replacement and PDE5Is may independently reduce all-cause mortality in T2DM

Panel on Impotence. JAMA 1993;270(1):83-90

http://dx.doi.org/10.1001/jama.1993.03510010089036

2. Feldman HA, Goldstein I, Hatzichristou DG, et al. Impotence and its medical and psychosocial correlates: results of the Massachusetts Male Aging Study. J Urol 1994:151(1):54-61.

3. McCulloch DK, Campbell IW, Wu FC, et al. The prevalence of diabetic impotence. Diabetologia 1980;18(4):279-83. http://dx.doi.org/10.1007/BF00251005

4. Sasaki H, Yamasaki H, Ogawa K, et al. Prevalence and risk factors for erectile dysfunction in Japanese diabetics. Diabetes Res Clin Pract 2005;70(1):81-9. http://dx.doi.org/10.1016/j.diabres.2005.02.018

5. Malavige LS, Levy JC. Erectile dysfunction in diabetes mellitus. J Sex Med 2009;6(5):1232-47. http://dx.doi.org/10.1111/j.1743-6109.2008.01168.x

6. Anderson RJ, Freedland KE, Clouse RE, et al. The prevalence of comorbid depression in adults with diabetes: a meta-analysis. Diabetes Care 2001;24(6):1069-78. http://dx.doi.org/10.2337/diacare.24.6.1069

7. de Groot M, Anderson R, Freedland KE, et al. Association of depression and diabetes complications: a meta-analysis. Psychosom Med 2001;63(4):619-30. http://dx.doi.org/10.1097/00006842-200107000-00015

8. Miner M, Seftel AD, Nehra A, et al. Prognostic utility of erectile dysfunction for cardiovascular disease in younger men and those with diabetes. Am Heart J 2012;164(1):21-8 http://dx.doi.org/10.1016/j.ahj.2012.04.006

9. Kirby M, Jackson $\mathrm{G}$. Erectile dysfunction as a predictor of coronary artery disease. Trends Urol Men's Health 2011;2(4):19-23. http://dx.doi.org/10.1002/tre.208

10. Saenz de Tejada. Anatomy, physiology and pathophysiology of ED. In: Jardin A et al, eds. Erectile dysfunction. Plymouth, UK: Plymbridge, 2000; pp 65-102.

11. Vlachopoulos CV, Terentes-Printzios DG, loakeimidis NK, et al. Prediction of cardiovascular events and all-cause mortality with erectile dysfunction: a systematic review and meta-analysis of cohort studies. Circulation Cardiovasc Qual Outcomes 2013;6(1):99-109. http://dx.doi.org/10.1161/CIRCOUTCOMES.112.966903

12. Gazzaruso C, Solerte SB, Pujia A, et al. Erectile dysfunction as a predictor of cardiovascular events and death in diabetic patients with angiographically proven asymptomatic coronary artery disease: a potential protective role for statins and 5-phosphodiesterase inhibitors. J Am Coll Cardiol 2008;51(21):2040-4. http://dx.doi.org/10.1016/j.jacc.2007.10.069

13. Inman BA, Sauver JLS, Jacobson DJ, et al. A population-based, longitu- 
dinal study of erectile dysfunction and future coronary artery disease. Mayo Clinic Proc 2009;84(2):108-13. http://dx.doi.org/10.4065/84.2

14. Montorsi P, Montorsi F, Schulman CC. Is erectile dysfunction the "tip of the iceberg" of a systemic vascular disorder? Eur Urol 2003;44:352-4 http://dx.doi.org/10.1016/S0302-2838(03)00307-5

15. Chew K-K, Finn J, Stuckey B, et al. Erectile dysfunction as a predictor for subsequent atherosclerotic cardiovascular events: findings from a linkeddata study. J Sex Med 2010;7(1 Pt 1):192-202. http://dx.doi.org/10.1111/j.1743-6109.2009.01576.x

16. Ma RC-W, So W-Y, Yang $X$, et al. Erectile dysfunction predicts coronary heart disease in type 2 diabetes. J Am Coll Cardiol 2008:51(21):2045-50. http://dx.doi.org/10.1016/j.jacc.2008.02.051

17. Araujo AB, Hall SA, Ganz P, et al. Does erectile dysfunction contribute to cardiovascular disease risk prediction beyond the Framingham risk score? J Am Coll Cardiol 2010;55(4):350-6.

http://dx.doi.org/10.1016/10.1016/j.jacc.2009.08.058

18. Nehra A, Jackson G, Miner M, et al. The Princeton III Consensus recommendations for the management of erectile dysfunction and cardiovascular disease. Mayo Clinic Proc 2012;87(8):766-78. http://dx.doi.org/10.1016/j.mayocp.2012.06.015

19. Jackson G, Nehra A, Miner M, et al. The assessment of vascular risk in men with erectile dysfunction: the role of the cardiologist and general physician. Int J Clin Pract 2013;67(11):1163-72. http://dx.doi.org/10.1111/ijcp.12200

20. Lu C-C, Jiann B-P, Sun C-C, et al. Association of glycemic control with risk of erectile dysfunction in men with type 2 diabetes. J Sex Med 2009;6(6):1719-28. http://dx.doi.org/10.1111/j.1743-6109.2009.01219.x

21. Esposito K, Ciotola M, Giugliano F, et al. Endothelial microparticles correlate with erectile dysfunction in diabetic men. Int J Impot Res 2007;19(2):161-6. http://dx.doi.org/10.1038/sj.ijir.3901500

22. Phé $V$, Rouprêt $M$. Erectile dysfunction and diabetes: a review of the current evidence-based medicine and a synthesis of the main available therapies. Diabetes Metab 2012;38(1):1-13. http://dx. doi.org/10.1016/j.diabet.2011.09.003

23. Düsing R. Effect of the angiotensin II antagonist valsartan on sexual function in hypertensive men. Blood Pressure Suppl 2003;2:29-34 http://dx.doi.org/10.1080/08038020310021967

24. Hackett GI, Cole NS, Deshpande AA, et al. Biochemical hypogonadism in men with type 2 diabetes in primary care practice. $\mathrm{Br} J$ Diabetes VasC Dis 2009:9(5):226-31. http://dx.doi.org/10.1177/1474651409342635

25. Home P, Mant J, Diaz J, et al. Management of type 2 diabetes: summary of updated NICE guidance. BMJ (Clin Res Ed) 2008:336(7656):1306-08. http://dx.doi.org/10.1016/10.1136/bmj.39560.442095.AD

26. Stellato RK, Feldman HA, Hamdy O, et al. Testosterone, sex hormonebinding globulin, and the development of type 2 diabetes in middle-aged men: prospective results from the Massachusetts male aging study. Diabetes Care 2000;23(4):490-4. http://dx.doi.org/10.2337/diacare. 23.4.490

27. Selvin $E$, Feinleib $M$, Zhang $L$, et al. Androgens and diabetes in men: results from the Third National Health and Nutrition Examination Survey (NHANES III). Diabetes Care 2007;30(2):234-8. http://dx.doi.org/10.2337/dc06-1579

28. Hackett G, Cole N, Bhartia M, et al. The response to testosterone undecanoate in men with type 2 diabetes is dependent on achieving threshold serum levels (the BLAST study). Int J Clin Pract 2014;68(2):203-15. http://dx.doi.org/10.1016/10.1111/ijcp.12235

29. Buvat J, Montorsi F, Maggi M, et al. Hypogonadal men nonresponders to the PDE5 inhibitor tadalafil benefit from normalization of testosterone levels with a $1 \%$ hydroalcoholic testosterone gel in the treatment of erectile dysfunction (TADTEST study). J Sex Med 2011;8(1):284-93. http://dx.doi.org/10.1111/j.1743-6109.2010.01956.x

30. Saad F, Aversa A, Isidori AM, et al. Onset of effects of testosterone treatment and time span until maximum effects are achieved. Eur J Endocrinol 2011;165(5):675-85. http://dx.doi.org/10.1530/EJE-11-0221

31. Hackett G, Cole N, Bhartia M, et al. Testosterone replacement therapy with long-acting testosterone undecanoate improves sexual function and quality-of-life parameters vs. placebo in a population of men with type 2 diabetes. J Sex Med 2013;10(6):1612-27. http://dx.doi.org/10.1111/jsm.12146

32. Hackett G, Cole N, Bhartia M, et al. Testosterone replacement therapy improves metabolic parameters in hypogonadal men with type 2 diabetes but not in men with coexisting depression: the BLAST study. J Sex Med 2014;11(3):840-56. http://dx.doi.org/10.1111/ssm.12404

33. Heufelder AE, Saad F, Bunck MC, et al. Fifty-two-week treatment with diet and exercise plus transdermal testosterone reverses the metabolic syndrome and improves glycemic control in men with newly diagnosed type 2 diabetes and subnormal plasma testosterone. I Androl 2009:30(6):726-33. http://dx. doi.org/10.2164/jandrol.108.007005

34. Kalinchenko SY, Tishova YA, Mskhalaya GJ, et al. Effects of testosterone supplementation on markers of the metabolic syndrome and inflammation in hypogonadal men with the metabolic syndrome: the doubleblinded placebo-controlled Moscow study. Clin Endocrinol 2010;73(5): 602-12. http://dx.doi.org/10.1111/j.1365-2265.2010.03845.x

35. Corona G, Giorda CB, Cucinotta D, et al. Sexual dysfunction at the onset of type 2 diabetes: the interplay of depression, hormonal and cardiovascular factors. J Sex Med 2014;11(8):2065-73. http://dx.doi.org/10.1111/jsm.12601

36. Drivsholm T, de Fine Olivarius N, Nielsen ABS, et al. Symptoms, signs and complications in newly diagnosed type 2 diabetic patients, and their relationship to glycaemia, blood pressure and weight. Diabetologia 2005;48(2):210-14. http://dx. doi.org/10.1007/s00125-004-1625-y

37. Arafa M, Eid H, El-Badry A, et al. The prevalence of Peyronie's disease in diabetic patients with erectile dysfunction. Int J Impot Res 2007; 19(2):213-17. http://dx.doi.org/10.1038/sj.ijir.3901518

38. Wing RR, Rosen RC, Fava JL, et al. Effects of weight loss intervention on erectile function in older men with type 2 diabetes in the Look AHEAD trial. J Sexual Med 2010;7(1 Pt 1):156-65. http://dx.doi.org/10.1111/j.1743-6109.2009.01458.x

39. Hackett G, Kell P, Ralph D, et al. British Society for Sexual Medicine guidelines on the management of erectile dysfunction. J Sex Med 2008;5(8):1841-65. http://dx.doi.org/10.1111/j.1743-6109.2008.00773.x

40. Price $D$, Hackett G. Management of erectile dysfunction in diabetes: an update for 2008. Current Diabetes Reports 2008:8(6):437-43. http://dx.doi.org/10.1007/s11892-008-0076-0

41. Thethi TK, Asafu-Adjaye NO, Fonseca VA. Erectile dysfunction. Clin Diabetes 2005;23(3):105-13. http://dx. doi.org/10.2337/diaclin.23.3.105

42. Hamidi Madani A, Asadolahzade A, Mokhtari G, et al. Assessment of the efficacy of combination therapy with folic acid and tadalafil for the management of erectile dysfunction in men with type 2 diabetes mellitus. J Sex Med 2013;10(4):1146-50. http://dx. doi.org/10.1111/ jsm.12047

43. Cui $H$, Liu B, Song Z, et al. Efficacy and safety of long-term tadalafil 5 $\mathrm{mg}$ once daily combined with sildenafil $50 \mathrm{mg}$ as needed at the early stage of treatment for patients with erectile dysfunction. Andrologia 2015;47(1):20-4. http://dx.doi.org/10.1111/and.12216

44. Vlachopoulos $C$, loakeimidis N, Rokkas K, et al. Cardiovascular effects of phosphodiesterase type 5 inhibitors. J Sex Med 2009;6(3):658-74. http://dx.doi.org/10.1111/j.1743-6109.2008.01107.x

45. Giannetta E, Feola T, Gianfrilli D, et al. Is chronic inhibition of phosphodiesterase type 5 cardioprotective and safe? A meta-analysis of randomized controlled trials. BMC Med 2014;12:185. http://dx.doi.org/10.1186/s12916-014-0185-3

46. Anderson SG, Hutchings DC, Kwok CS, Trafford AW HA. Phosphodiesterase type $V$ inhibitors use in type 2 diabetes is associated with reduced all-cause mortality. Poster LBA-9, ADA, 2015.

47. Shores MM, Smith NL, Forsberg CW, et al. Testosterone treatment and mortality in men with low testosterone levels. J Clin Endocrinol Metab 2012;97(6):2050-08. http://dx.doi.org/10.1210/jc.2011-2591

48. Muraleedharan V, Marsh H, Kapoor D, et al. Testosterone deficiency is associated with increased risk of mortality and testosterone replacement improves survival in men with type 2 diabetes. Eur J Endocrinol 2013;169(6):725-33. http://dx.doi.org/10.1530/EJE-13-0321

49. Anderson JL, May HT, Lappe DL, et al. Cardiovascular impact of testosterone therapy in men with low testosterone levels (abstract). Circulation 2014;130(Suppl 2):A13220. 